\title{
Primary Mathematics Teachers' Understanding of Computational Thinking
}

\author{
Siri Krogh Nordby ${ }^{1}\left[\right.$. Annette Hessen Bjerke ${ }^{1}\left[\right.$ [ Louise Mifsud ${ }^{1}[$
}

Received: 9 July 2021 / Accepted: 9 December 2021 / Published online: 23 February 2022

(c) The Author(s) 2022

\begin{abstract}
Computational thinking (CT) is often regarded as providing a 'soft start' for later involvement with artificial intelligence and, hence, as a crucial twenty-first century skill. The introduction of CT in primary mathematics curricula puts many demands on teachers, and their understanding of CT in mathematics is key to its successful introduction. Inspired by an information ecology perspective, we investigate how four primary school teachers understand CT in mathematics and how they go ahead to include CT in their mathematics teaching practice. Through observations and interviews, we find promising starting points for including $\mathrm{CT}$, related to pattern recognition, problem solving and the use of programming activities. Our findings indicate that teachers' lack of knowledge affects CT adoption in two ways: during its inclusion in the existing mathematics curriculum and as a new element focussed on programming and coding, leaving mathematics in the background. For the inclusion to be fruitful, we suggest there is a need to help teachers understand how CT can be used productively in mathematics and vice versa.
\end{abstract}

Keywords Artificial intelligence $\cdot$ Computational thinking $\cdot$ Primary school $\cdot$ Mathematics education $\cdot$ Mathematics teachers

\section{Introduction}

Artificial intelligence (AI) plays an important role in society, being used in everything from maps and smartphones to search engines, smart refrigerators, and virtual assistants. AI can be described as the development or creation of computers that are able to engage or perform imaginable human jobs and human-like thought processes such as learning, reasoning and self-correction [1].

According to Papert [3] computational thinking (CT) helps students to gain access to powerful ideas in procedural thinking in writing programs. Kandlhofer et al. [2] argue that it is necessary to introduce AI at an early stage in school in order to familiarize children with basic concepts of AI/

Siri Krogh Nordby

Siri-Krogh.Nordby@ oslomet.no

Annette Hessen Bjerke

Annette.Hessen@oslomet.no

Louise Mifsud

Louise.Mifsud@oslomet.no

1 Oslo Metropolitan University, Oslo, Norway computer science and developing underlying concepts of AI literacy. This highlights a relationship between AI and CT. For instance, developing a self-driving car includes building computational systems of how the car moves and interacts. Gadanidis [4] suggests that conceptualizing models building such systems requires skills in CT; he claims that CT is not distinct or separate from AI but that the two can be seen through the lenses of each other.

In line with this, $\mathrm{Yu}$ and $\mathrm{Chen} \mathrm{[5]} \mathrm{stress} \mathrm{that} \mathrm{CT}$ is central to gaining literacy in the field of information technology and reflects the intrinsic values of the AI curriculum, which is taught at the high school level. While AI refers to the intelligence evident in machines or software and is often focussed on in higher grades [4], CT is considered a skill that can be added 'to every child's analytical ability' [6 p. 33] and, therefore, can be included from the early years of primary education. CT is described as a skill that goes beyond computer science, as CT 'represents a universally applicable attitude and skill set for everyone' [6 p. 33], referring to a set of thinking skills, processes and approaches that can be used to solve complex problems by drawing on concepts from computer science [6]. Rich et al. [8] argue that the rationale for including $\mathrm{CT}$ in education is our increasingly 
computer-oriented world, in which students need to 'understand principles of how a computer works and [what] kinds of problems that could be solved computationally' [8 $\mathrm{p}$. 165]. In this way, CT can provide a 'soft start,' setting the stage for later involvement with AI. This is reflected in the rising interest in bringing $\mathrm{CT}$ into educational contexts and school curricula in recent years [7].

Some countries have included CT as its own subject, while others have embedded it in current subjects such as mathematics and information technology, and a key question is how to best prepare and support teachers to include CT into their teaching practices [9]. Several professional development efforts have been conducted to help teachers implementing CT [e.g. 10,11] and these studies suggest that there is a need to upskill teachers and give specific guidance. However, research on how in-service teachers understand and adapt $\mathrm{CT}$ in their teaching practice is limited.

Norway introduced CT into the mathematics curriculum in 2020. In this paper, we explore mathematics teachers' understanding of $\mathrm{CT}$ as part of the mathematics curriculum three months after its introduction, as well as throughout the scholastic year. Due to teachers' difficulties in integrating mathematics and CT [12] and their sparse knowledge on how to implement CT in their teaching [13], we follow up on Bocconi et al.s' [9] call for more knowledge on how to prepare and support teachers in including $\mathrm{CT}$ in their teaching practices. We do this by exploring teachers' first efforts of integrating CT in the teaching of mathematics. Our aim is to investigate teachers' initial understanding of CT and how they go ahead to include CT in their mathematics teaching practices.

\section{Literature Review}

$\mathrm{CT}$ in an educational context is not new, as it originated with Papert in 1980 [3]. In framing CT in an educational context, Wing [6] suggested that CT includes solving problems, designing systems and understanding human behaviour. In the wake of the resurgence of interest in CT, several definitions have emerged, leading to a new concern: ensuring a coherent shared understanding of CT [14-18]. Haseski et al. [16] conducted a content analysis of the definitions of CT in publications up to 2016-spanning various categories from problem solving to technology utilisation and thinking strategies-and found 59 different definitions. However, the different definitions did share some common underlying features, such as their relation to problem solving $[28,16]$ and their thought processes that involve expressing a solution as computational steps or algorithms, which would usually be carried out by a computer [19]. Through the broad lens of problem solving, definitions of CT move towards providing a foundation within the realm of AI by emphasising different aspects of intelligent automation-for example, CT being 'a problem-solving methodology that can be automated and transferred and applied across subjects' [20 p. 51], and CT using algorithms or simulations [14, 15, 21].

Even though a shared understanding of $\mathrm{CT}$ in education has not yet been established, a review of the literature shows that there are frequent references to the use of three types of activities: screen-based computer programming [8, 22], digital tangibles such as programmable robots and circuits; $[23,24]$ and, more generally, the off-screen design of algorithms or pseudocodes $[25,26]$. While most of the empirical studies on the development of CT among students have been conducted in high school contexts [27] fewer are situated in primary school contexts. In a systematic review of empirical studies of CT in primary mathematics between 2015 and 2020, Nordby et al. [28] found only 10 empirical studies of $\mathrm{CT}$ in primary school mathematics. However, the existing studies did show that screen-based computer programming and digital tangibles were dominant in primary mathematics classrooms, and that most CT interventions were led by researchers rather than the teachers themselves [28]. Consequently, Nordby et al. [28] raised the question of whether teachers lack CT proficiency and what challenges they face in relation to their CT expertise. Adding to these concerns, after analysing 47 lesson plans in mathematics across grades $1-5$, Israel and Lash [12] found that the majority of the lessons did not include any integration of mathematics and $\mathrm{CT}$ - the lessons focussed either on mathematics (less often) or on CT (more often).

Research focusing on teachers' understanding of CT in mathematics at the primary school level is sparse. Sands et al. [13] used a survey to examine 74 in-service teachers' conceptions of CT. They found that teachers have little knowledge about what $\mathrm{CT}$ entails and how to implement $\mathrm{CT}$ in their teaching. Similar findings were reported in a study conducted by Reichert et al. [29]. In their case study of 28 mathematics teachers, the teachers were willing to include CT in mathematics but lacked knowledge about how to include it.

Rich et al. [8] presented an in-depth qualitative study investigating what 12 elementary school teachers thought about integrating $\mathrm{CT}$ in their existing elementary school curricula. Using the description of Bocconi et al. [9] of the key components of CT as their point of departure, the teachers were asked to comment on how these key components fit their existing mathematical and science practices, revealing that the teachers most often related CT to problem solving. This is not surprising. A recent review investigating CT in mathematical problem solving in $\mathrm{K}-12$ education found that problem solving is an important and fundamental term within both CT and mathematics; this overlap forms the base of the well-established argument for integrating CT in mathematics [Refvik \& Bjerke, submitted]. Despite this stated 'bridge' between mathematics and CT, Rich et al. [8] 
reported on the related challenges, such as concerns about how to bring $\mathrm{CT}$ into mathematics teaching in a way that results in high-level CT in students. Taken together, we see that there is a need to focus more on teachers' knowledge and understanding of CT.

\subsection{Background}

A report initiated by the Norwegian Government argued that if Norwegian schools are to keep pace with the rapid development in digital systems, digital competence must be included in existing school subjects [30]. Norway introduced CT in a revised curriculum in autumn 2020, with explicitly visible CT competence goals in mathematics. Acknowledging that such substantial changes in curricula put many demands on teachers [30], a work package was developed by the Norwegian Ministry of Education and made available online for teachers to use [31].

Adding to the complexity that comes from the many different definitions of CT, in the Norwegian curriculum, CT was translated as algoritmisk tenkning (algorithmic thinking ${ }^{1}$ ). This has muddied the waters further, mainly due to the association of this term with standard algorithms in mathematics. In the curriculum, algorithmic thinking (or CT) is operationalised as follows:

- Create and follow rules and step-by-step instructions in play and games (by the end of Grade 2).

- Create and follow rules and step-by-step instructions in play and games related to the coordinate system and explore and describe structures and patterns in play and games (by the end of Grade 3).

- Create algorithms and express them using variables, conditions and loops (by the end of Grade 4).

After Grade 4, programming (building on the three above points) is mentioned in all stages in the primary education curriculum as a tool for working with CT in mathematics.

\subsection{Research Question}

Our study is inspired by an information ecology perspective, wherein an information ecology is looked upon as a 'system of people, practices, values, and technologies in a particular local environment' [32 p. 49]. Applying a metaphorical use of the term ecologies, Nardi and O'Day [32] argued that in information ecology, the spotlight is not on technology but on human activities that are served by technology, wherein

\footnotetext{
${ }^{1}$ Algorithmic thinking in this paper refers to the Norwegian translation of CT. Algorithmic thinking is understood differently in research papers about $\mathrm{CT}$.
}

the social and the technical co-evolve, and people's activities and tools adjust in an attempt to fit.

Nardi and O'Day [32] pointed out that a change in an ecology is 'systemic', as changing one element affects the whole system. Hence, the introduction of a new element may change the whole system; some of these changes, whether negative, positive or neutral, may be unintended. Taking an information ecology perspective allows for an understanding of the complexity of the classroom, wherein CT is a new element that is being introduced and embedded in an established context. Carrying the analogy further, the introduction of a new curriculum defines a new, and current, set of core values for the people who inhabit the classroom ecology, including both the teachers (who have to implement the curriculum) and the students (who are at the receiving end). Understanding how a tool, such as CT, that is entering an established setting may or may not fit in, is crucial to understanding the practices and activities that will emerge. As gatekeepers to practices and activities in the classroom, teachers may take on the role of being either gate openers or gate closers with regards to CT. For instance, Larke's [33] study of programming in English schools found that 'teachers have acted as gatekeepers to block a curriculum that they view as narrow, difficult to teach and in conflict with their beliefs and practices as educational professionals' [33 p. 1137].

Keeping in mind that $\mathrm{CT}$ is relatively new to educators in general, and that Norway has recently introduced CT into their new mathematics curriculum, we find it important to investigate the teachers' roles as gatekeepers and give them a voice in the matter. Given the argument that CT is a fundamental skill that everybody should learn to meet the digital demands in society, it is crucial to know more about teachers' understanding of CT and its inclusion in already established classroom ecologies. By this, we acknowledge their pivotal role in the quality of the integration.

In this paper, we conduct an in-depth investigation of primary mathematics teachers' understanding of CT and how they include CT in their mathematics teaching practices. The above literature reveals the opportunities and challenges encountered when implementing CT in curricula; hence, we argue that it is important to investigate how teachers understand their curricular needs and how they can be looked upon as gate openers for their students in developing CT through the subject of mathematics and, consequently, AI knowledge. This study aims to answer the following research question:

How do primary school teachers understand the integration of CT in their mathematics teaching practices? 
Table 1 Participants

\begin{tabular}{|c|c|c|c|c|c|c|}
\hline Teacher & Grade & $\begin{array}{l}\text { Number } \\
\text { of pupils }\end{array}$ & $\mathrm{CT}$ resources & $\begin{array}{l}\text { Years of teach- } \\
\text { ing experience }\end{array}$ & $\begin{array}{l}\text { Years of mathematics } \\
\text { teaching experience }\end{array}$ & $\begin{array}{l}\text { ECTS in } \\
\text { mathemat- } \\
\text { ics }\end{array}$ \\
\hline Kimmi & 4 & 24 & N/A & 26 & 26 & 30 \\
\hline Kyra & 4 & 20 & \multirow{2}{*}{$\begin{array}{l}\text { Textbook: Robot- } \\
\text { byen [Robot } \\
\text { city] }\end{array}$} & 19 & 7 & 30 \\
\hline Laura & 1 & 10 & & 8 & 1 & 45 \\
\hline Olivia & 4 & 15 & Hour of Code $\mathrm{e}^{\mathrm{a}}$ & 1.5 & 1.5 & 60 \\
\hline
\end{tabular}

${ }^{a}$ Hour of Code is a non-commercial initiative aimed at school students to provide insight into programming (see https://hourofcode.com/no).

\section{Methodology}

\subsection{Participants and Data Collection}

In this paper, we draw on two sets of data: semi-structured interviews with four primary school teachers (grades 1-4) conducted 3 months after the introduction of CT in mathematics classrooms in Norway, and non-participant observations of their teaching the following spring. The first author contacted 20 schools in the southern part of Norway which all had Information, Communications and Technology (ICT) as one of their focus areas. Two teachers from two different schools were recruited through this method. The other two teachers heard about the project and initiated contact with the first author. The teachers' mathematics teaching experiences ranged between 1 and 26 years, and none of the teachers had any formal education in programming, computer science or CT (see Table 1).

The interviews were conducted online by the first author and lasted for about $30 \mathrm{~min}$. The overall intention was to capture how teachers understand the introduction of $\mathrm{CT}$ in mathematics, and key topics were as follows: their understanding of algorithmic thinking/CT as it appears in the national curriculum; how they see the connection between CT and mathematics; and which sources they draw upon when implementing CT in mathematics.

The first author observed, and video recorded the four teachers in mathematics classes in lessons where CT was included. A video camera was placed in the back of the classroom, capturing teachers' activity and instructions. Audio was obtained with a wireless microphone that was attached to the teacher. An overview of the observations is given in Table 2, together with a summary of the pre- and post-observation conversations that the first author had with each teacher before and after each observed lesson where possible (in which questions such as, "What is the goal of the lesson?' and 'In what way is CT emphasised in this session?' were raised). As Table 2 reveals, pre- and post-observation conversations were not always possible, for instance with Olivia where she had schoolyard duties prior to the lesson and a new lesson right after. Both the interviews and the pre- and post-observation conversations and observations were transcribed in full in their original language (Norwegian) by the first author.

\subsection{Data Analysis}

We employed a case study approach [34] as a way of studying the thoughts and actions of the primary school teachers to capture how they understand the introduction of CT in mathematics. The analysis was conducted in three steps, following Neuman's [35] qualitative coding techniques.

First, the transcribed interviews and observations were analysed by the first author using the software HyperResearch. Focussing on the teachers' understanding, an opencoding approach was used to capture their ideas and understanding of different CT concepts and their utterances about, for instance, attitudes, knowledge, and mathematical content. This initial coding resulted in 34 different codes that were discussed amongst the three authors.

In the second step, axial coding was carried out to determine emergent themes by grouping the codes from step one. All three authors were involved in this step, resulting in a refinement of the codes from step one and allowing us to revisit the data several times.

Table 2 Data collection

\begin{tabular}{|c|c|c|c|c|c|}
\hline & \multicolumn{3}{|c|}{$\begin{array}{l}\text { Pre- and post- } \\
\text { observation } \\
\text { conversations }\end{array}$} & \multicolumn{2}{|l|}{ Observation } \\
\hline & Pre & Post & Length & Content & Length \\
\hline Kimmi & 0 & 1 & $3 \min$ & $\begin{array}{l}\text { A.Figure numbers } \\
\text { A.Multiplication }\end{array}$ & $\begin{array}{l}60 \mathrm{~min} \\
80 \mathrm{~min}\end{array}$ \\
\hline Kyra & 1 & 0 & $3 \min$ & $\begin{array}{l}\text { A.Unplugged programming } \\
\text { B.Unplugged programming }\end{array}$ & $\begin{array}{l}60 \mathrm{~min} \\
60 \mathrm{~min}\end{array}$ \\
\hline Laura & 1 & 1 & $4 \min$ & $\begin{array}{l}\text { A.Unplugged programming } \\
\text { B.Unplugged programming } \\
\text { C.Unplugged programming } \\
\text { D.Unplugged programming }\end{array}$ & $\begin{array}{l}30 \mathrm{~min} \\
40 \mathrm{~min} \\
30 \mathrm{~min} \\
30 \mathrm{~min}\end{array}$ \\
\hline Olivia & 0 & 0 & N/A & A.Screen-based programming & $75 \mathrm{~min}$ \\
\hline
\end{tabular}


In step three, the selective coding phase, we settled on four main themes. In doing so, we revisited the data once more, filling in categories that needed further refinement and development. The first theme, teachers' understanding of $C T$, captured teachers' understanding of different CT-related concepts and approaches (e.g., problem solving, algorithms, patterns and debugging). The second theme, teachers' views on knowledge, consisted of the various aspects of knowledge that appear in teachers' understanding (e.g., utterances about their knowledge of the revised curriculum and their own knowledge). The third theme, teachers' emotional utterances, included their feelings related to implementing CT in their mathematics teaching and was associated with words such as positive, reluctant, nervous and stressed, among others. The fourth theme, teachers' understanding of possible activities related to $C T$, captured teachers' understanding of the strategies, techniques, choices, and pedagogical ideas related to the implementation of CT in mathematics teaching. Phrases that were coded in this theme were related to the types of resources on which the teachers draw.

To ensure validity, we used both investigator and data triangulation [34]. While the first author collected and transcribed the data, all three authors were involved in all but the first step of data analysis (as described in detail above). All the themes and codes were discussed until agreement was reached, often resulting in a re-reading of the original transcripts. The data triangulation ensured that the results from the interview data were supported by the observation data, and vice versa.

In presenting our analysis, we are necessarily limited to illustrative quotes only. Excerpts presented in the results were selected on the basis of their typicality; that is, an excerpt was chosen if it was illustrative of utterances that were typical across the data material or if it presented a view that was atypical. To ensure that such quotes were representative of the trends identified across the group of teachers, we aimed to stay close to our research questions and to make sure that all teachers were represented in the reporting. Passages selected for further analysis and reporting were then translated into English and each translation was discussed between the authors to safeguard the original meaning.

The overall project was given full ethics approval by the Norwegian Social Science Data Service, ensuring the interests of the participants. We are aware of the limitations of this study, which are mainly connected to the small number of interviews conducted with only female teachers, ${ }^{2}$ and we are mindful of the limits to the generalisability of our results. However, we propose that our findings can provide insight

\footnotetext{
2 The proportion of women in Norwegian primary school is $74.4 \%$ [29]; see https://www.ssb.no/utdanning/barnehager/statistikk/ansat te-i-barnehage-og-skole).
}

into how primary school teachers understand the introduction of CT in mathematics three months after the inclusion of CT in mathematics in Norwegian primary schools.

\section{Results}

By viewing the mathematics classroom in terms of a wellestablished ecology, inspired by Nardi and O'Day [32], we highlight how the introduction of CT may affect pre-existing, habitual classroom activities. With this in mind, we start this section by investigating teachers' understanding of CT, before we examine teachers' views on the related knowledge and their emotional utterances. We end the section by presenting a description of the possibilities that teachers have noticed in conjunction with the introduction of CT in mathematics, while acknowledging the need for adjustments in their attempt to make CT fit in the mathematics classroom.

\subsection{Teachers' Understanding of CT}

Our data reveals that the teachers struggled to determine what 'algorithmic thinking', or CT, is and, hence, how to connect CT and mathematics. In terms of CT 'invading' an established ecology, this struggle to understand what CT is also means that it is difficult for the teachers to determine CT's place. Due to this disparity, drawing on both interview and classroom data, our findings indicate that teachers' understanding needs to be understood a) in connection to programming, and b) in connection to mathematics.

The teachers in our study discussed algorithms both in terms of following and in terms of creating instructions. When planning mathematics lessons that involved CT, both Laura and Kyra relied heavily on instructions given in a textbook that their school used. This textbook followed a plot: freeing robots from captivity. The book emphasised to students and assured teachers that the included tasks focussed on problem solving, algorithmic thinking, programming and mathematical skills. Drawing on this textbook, Laura explained to her students that they had 'been given a code to follow' (Laura, observation 1, 05:25), while Kyra described to her Grade 4 students that they had to 'follow some kind of written code enabling the robots to escape' (Kyra, observation 1, 00:30). Their explanations were given exclusively with reference to the textbook, without any additional efforts to connect the tasks to mathematics (but, as noted above, the textbook did that job for them).

When creating algorithms, Olivia, using Hour of Code, instructed one of her Grade 4 students to leave the classroom while the rest of the class created a code for the student to follow upon re-entering the classroom: 'Go five steps right ahead, then another two. Turn right 90 
degrees, go three steps straight ahead. Lift your right arm...' (Olivia, observation 1, 26:15).

One of the overarching goals in Olivia's lesson was for her students to learn programming skills such as loops and sequences. The above activity and its instructions were intended to illustrate how to create algorithms and to show the outcome of such algorithms. The excerpt demonstrates how the introduction of a new element into the curriculum was party to the creation of new activities in the mathematics classroom, with limited effort from the teacher to connect it to mathematics.

Kimmi took a somewhat different approach. She interpreted working with algorithms (as in algorithmic thinking) as something similar to working with standard algorithms (Kyra and Olivia also reported a similar understanding in their interviews). This was visible in both of Kimmi's CT lessons. She talked her students in Grade 4 through the standard algorithm for multiplication, solving the Eq. $15 \times 6$ : 'Begin with the ones place: six times five is thirty. Then, multiply by ten, and therefore, put a zero below. Six times one is six. Finally, add them together: thirty plus sixty equals ninety' (Kimmi, observation 2 , 21:00).

In doing this, she reasoned that she had included algorithmic thinking, or CT, in her teaching. In the same manner, she argued that she teaches her students CT by explaining how pattern recognition (teaching figure numbers) and trial and error (using word problems) are activities that we already do in mathematics: 'What I think [CT] is, is that one should, in a way, increase the understanding of numbers, perhaps by seeing patterns in numbers and playing around a bit' (Kimmi, interview 2, 02:26).

As such, she reasoned, because the algorithmic thinking is 'already there', there is no need to add anything to 'tick off' the added competence goals in the curriculum following the inclusion of CT in mathematics.

The same was true, in Kimmi's view, for problem solving: 'But algorithmic thinking... I would think that there are procedures [in algorithmic thinking] to solve problemsthat there are many ways to solve different types of tasks' (Kimmi, interview 1, 02:14). Because problem solving is an established method used in mathematics education, it appears that Kimmi understood CT to be connected to problem solving, which was already included in her teaching. In the same manner, Kyra suggested the following: 'Perhaps it $[\mathrm{CT}]$ involves problem solving, but in a different way to how we work with it [now, before CT], but I don't know' (Kyra, interview 1, 03:31).

Although the teachers, during the interviews, related CT to algorithmic thinking and problem solving and argued that CT was already present in the curriculum, it turned out somewhat differently in Kyra, Laura and Olivia's lessons. Kyra stayed close to the textbook and gave her students a map and a set of five codes. Their task, addressing trial and error, was to find the correct order of the codes:

Here, you have the codes: one, two, three, four, five codes. Their order is incorrect, so you have to figure out which of the codes has to come first. You have to use the map to find out where the start is and where you are supposed to end up. (Kyra, observation 2, 13:00)

Kyra's instructions are also illustrative of the way in which Olivia described decomposition ('Yes, [it's] a rather long and difficult goal. It's about breaking [something] down to the smallest detail to get your agent to do exactly what you say. Break it down in detail' [Olivia, observation 1, 04.11]), the way in which Laura addressed loops ('to repeat a sequence' [Laura, observation 3,02:15]) and the way in which Olivia described sequences ('to do something that results in an action' [Olivia, observation 1, 03:40]). All these explanations were given without any reference to mathematics; Kyra, Laura and Olivia all addressed these CT concepts as being exclusively related to programming.

We found one exception to the disconnect between programming and mathematics: when addressing pattern recognition, Laura saw how the pattern recognition that is necessary when working with algorithmic thinking is already focussed on in 'established' mathematics classes:

Being able to see patterns ... creates a foundation. In fact, I think we do a lot on this already, without being conscious that this is what we are doing. ... Perhaps, in mathematics in Grade 1, disconnected from this [referring to the textbook on programming], I can see pattern recognition [. . .]. It is very relevant. (Laura, interview 3, 01:17)

Our data revealed two distinct understandings of CT: (1) $\mathrm{CT}$ as an add-on (i.e., it is understood as a first meeting with programming that is disconnected from mathematics, as it appeared in Kyra, Laura and Olivia's accounts), and (2) CT as an untreated component (i.e., it is understood as being covered by things that are already part of an everyday mathematics classroom, such as standard algorithms, as it appeared in Kimmi's account). These findings form a basis for how we understand the remaining three themes that emerged from our analysis; essentially, what the teachers understood CT to be is important as a backdrop when investigating what they said about their need for knowledge, their emotional utterances and the possibilities they saw for including CT in mathematics in their future teaching.

\subsection{Teachers' Views on Knowledge}

From an information ecology perspective, the introduction of CT initiated the need for knowledge. Our analysis 
revealed two categories of such knowledge change: that of the teachers, and that of the students.

All four teachers expressed uncertainty about how CT appears in the curriculum, either because they had not read the curriculum carefully enough or because they struggled to fully understand it. The former was highlighted by Kyra: 'I have read the [new] curriculum, but I do not remember it right now. But it probably says something about CT, I think' (Kyra, interview 1, 3:57).

The latter was expressed by Kimmi:

Earlier, I held the view that you always have to explain how you think when conducting word problems, but when I try to read a little about it now, it seems like it has to do with patterns, that it is about computers and formulas. But I cannot quite imagine what it really is. (Kimmi, interview 2, 04:17)

Both these utterances show a need for more knowledge to understand the role of CT in the curriculum and, as we shall see, for more knowledge about what $\mathrm{CT}$ is and how it can be included in mathematics instruction. While many of the teachers' shortcomings in teaching CT are disseminated in the previous section, we now draw on what they revealed about their need for more knowledge:

[I] do not know anything about it [CT] and have not been able to learn it by myself, and I have therefore not included it in my teaching. (Olivia, interview 1 , 08:13)

How would I manage to teach coding? Because I do not know what it is, almost. I am aware that we do not get any training to learn it because there is no money set aside for it. (Kyra, interview 1, 08:08)

It's not that I do not want to [include CT in my teaching] but that I do not know enough and lack awareness of it. (Laura, interview 1, 20:51)

The insecurity appeared even more clearly as they kept answering questions with questions, such as when Kyra was asked about which subjects in mathematics are best suited in the work with CT and answered, 'It's a bit related to functions, isn't it? In math?' (Kyra, interview 1, 08:00). Kimmi used the same counter-question approach: 'Could it be the four types of calculations?' (Kimmi, interview 1, 11:20).

When asking the teachers about external and internal upskilling opportunities, it seemed that both were absent. Even if the schools prepared teachers for the revised curricula, the teachers' utterances showed that they are not aware of how to include CT in mathematics:

There has been no upskilling in mathematics. I've never heard anyone talk about that term [CT] at [my] school. I have worked on it on my own ... with coding, a task I have just started. (Laura, interview 1, 05:40)
I have not been put on the subject of mathematics in the work with the new curricula [the teachers are split into different groups working on different subjects], so I have not worked with it at our school. (Olivia, interview $1,07: 30)$

This indicated that it is up to the teachers to take the initiative to understand how to implement CT into their mathematics teaching.

Added to the shortcomings in the teachers' own knowledge are their contrasting views of their students' knowledge. The teachers experienced their students to be fast learners and to have more knowledge about coding and programming than themselves:

I really think they [the students] have understood it very easily. Many of the students have understood it faster than me. It's quite intuitive because they seem to [understand it]; even if there's only one here doing some coding at home, they're pretty quick. (Kyra, interview 2, 2:20)

While Kyra was visibly impressed by her students, Olivia found her students' high level of knowledge challenging: 'the students [in Grade 4] have had an iPad since Grade 1, and they have code courses that may make them better than me. This makes the threshold level [of introducing CT] even higher [for me]'. (Olivia, interview 1, 20:13).

The classroom observations gave a similar impression, as Olivia repeatedly praised her students, stating at one point, 'Oh, you are so much better than me' (Olivia, observation 1, 30:30). She also used her students' knowledge as support when she struggled to help a student with a task. As seen in the following excerpt, Olivia specifically asked a student for help in solving a particular task:

Then it must be like that, right? I do not know if it's right—-try. No. . . . Did you try? Wait a minute. . . . [Olivia calls for another student] ... Come here. How do we get the agent to keep destroying things? (Olivia, observation 2, 54:10)

Although our data indicated that the teachers, to some extent, viewed their lack of knowledge as a hindrance to the inclusion of CT in their teaching, as we have seen above, three of the teachers made an effort to implement CT into their mathematics instruction anyway, either by following a textbook or through trial and error and asking for assistance from the students. In the following section, we take a closer look at the teachers' emotional utterances while navigating the inclusion of $\mathrm{CT}$ in mathematics education.

\subsection{Teachers' Emotional Utterances}

Drawing on Nardi and O'Day [32], as a newcomer, CT can inspire engagement and increased participation in new 
shared activities, or it can inspire the opposite-resistance. According to Nardi and O'Day [32], the two extremes are uncritical acceptance or blanket rejection. In our study, the teachers seemed to operate somewhere between these two extremes. This is not to say, however, that the way in which they navigated the inclusion of CT did not prompt emotional reactions in terms of, for example, nervousness or annoyance.

The data suggests that it was the teachers' lack of knowledge that evoked their emotions. To some extent, the teachers' lack of knowledge about what CT entails made them feel stressed, nervous and, at times, irritated, as the interviews with Kyra and Olivia showed:

I'm a bit unconfident not knowing what algorithmic thinking is. But if it's about coding, I get a little nervous, because this [coding] is something I know nothing about. I saw someone code something quite simply once; it's a bit related to functions, isn't it? In math? I do not know, I'm a little stressed about it; how do I manage to teach coding? Because I do not know what it is. (Kyra, interview 1, 07:48)

I feel it [the introduction of CT] can be disruptive because I have no knowledge about it, which makes it annoying. (Olivia, interview 1, 20:30)

In addition, the teachers expressed concerns related to the already packed mathematics curriculum; they argued that basic mathematics teaching needs to be in place before they can start introducing a 'foreign' element such as CT: 'There is so much basic [mathematics] that is missing, and I want them [the students] to learn that first, before I move on'. (Olivia, interview 1, 09:10).

However, during an observation session, Oliva seemed eager to motivate her students to engage in coding and programming:

You can build programs and games, and it is useful and educational and simply entertaining [... ]. You also learn to take control over the computer or the iPad. It is also [related to] how we live, the way you talk about work later in life-we live in a very technological world that is becoming more and more technological each year. Think about it: soon maybe cars or planes will drive by themselves. Then, it is technology and programming that is needed. (Olivia, observation 1, 14:27)

While Olivia sounded troubled by everything that needed to be done, Kimmi appeared to be calm and on top of things. Remembering that Kimmi was more reluctant and convinced that she already includes the necessary work on algorithmic thinking in her mathematics classes, she kept reassuring herself (or us) that no change is needed:
I have been in school for so long [26 years], and I have been through so many curricula, that I do not throw myself around thinking that everything is new. I use a lot of what I have done before. I know what's important for the kids to know when they finish Grade 7. (Kimmi, interview 1, 05:00)

The first three themes in this section gave an account of the teachers' understanding of CT, their views on their own knowledge about it (or lack thereof) and their emotional utterances in connection to the inclusion of CT in mathematics. In the next section, we report on what our data reveals about the possible activities the teachers' identified for use in teaching students CT; while not directly resistant to CT, the teachers relied heavily on existing teaching materials that they found, and they struggled to find a place for CT activities within the mathematics ecology.

\subsection{Teachers' Understanding of Possible Activities Related to CT}

Previous literature has suggested that the inclusion of CT in education often results in three different types of activities: screen-based activities, activities using tangibles/robots and off-screen/unplugged activities [23, 26, 36]. In our data, we identified the use of screen-based programming and unplugged activities.

Both Laura and Kyra's teaching activities were based on a textbook that contained only unplugged programming activities. Each reported following the textbook chapter by chapter, starting with chapter one. The goal given to students in the textbook was to free robots from captivity by solving different tasks, such as placing a code in the right order (sequencing):

You will be given this mission called Roberto's Revenge [a sheet with a map and some codes]. And here, you have the codes [she points to the bottom of the sheet]: one, two, three, four, five codes. Those codes are in the wrong order, so you need to find out which of these codes should be number one-which of these codes you have to start with first. You also need to look at the map to find out where the start is and where you have to move to solve the mission. (Kyra, observation 2, 09:20)

As we see in the above excerpt, the students were to reorder codes into the right sequence in an activity they performed using a grid on a piece of paper. Hence, there was no use of computers or tablets.

We only observed screen-based activities in Olivia's class. Her main goal was for her students to learn programming skills such as loops and sequences, and to be able to follow instructions using code blocks in Minecraft: 
Let's go into Minecraft [...]. Now, we come to the first page [referring to the first task shown on the screen]; we go into the code lesson and choose 2019, then push 'create world'. To find the agent, we click here, and we will use blocks. (Olivia, observation 1, 41:07)

Activities using tangibles and robots were only briefly mentioned, but not used, as the teachers' lack of knowledge stopped them from using such activities:

We have our own innovation room, where we have Lego robots that are supposed to fit all grade levels. We have Beebots, but [I] have not tried them. [I] cannot do it myself and have not been able to learn it, and I have, for that reason, not used it. (Olivia, interview 1,08:05)

As the above excerpt illustrates, the school had invested in CT equipment, but Olivia viewed the use of tangibles as a possibility that was not available to her because she had not 'been able to learn' how to use the robots. This resulted in her not using them in class. As such, Olivia assumed the role of gate closer with regard to using tangibles in the mathematics classroom, due to her lack of knowledge and competence in the field.

\section{Discussion}

Approaching the mathematics classroom as an established information ecology enabled us to investigate the introduction of CT as a conceptual tool and as a foreign element. This perspective allowed us to gain insight into what happens when teachers' habitual activities need to be adjusted in an attempt to fit the new content area (CT) within the established ecology. Building on Nardi and O'Day [32] metaphorical use of the term ecologies, we argue that CTwhich is at the starting line, just entering Norwegian primary mathematics classrooms-is about to be transformed into its own local ecology. This local ecology can be understood as a new, separate satellite orbiting the established mathematics ecology, creating confusion and uncertainty in teachers.

In this section, we revisit our research question that guided our work and discuss how our analysis shows how primary school teachers understand the integration of CT in their mathematics teaching practices.

The existing body of research presents a divergent understanding of CT [14-18]. The teachers in our study strove to understand both what $\mathrm{CT}$ is and what $\mathrm{CT}$ is supposed to be in mathematics. Our analysis indicates that the Norwegian translation of CT as algoritmisk tenkning (algorithmic thinking) leads to misunderstandings and misconceptions, as the term algorithm has associations with standard algorithms. In mathematics, algorithm is a common term referring to the use of standard procedures and standard methods to perform and solve routine arithmetic tasks. Consequently, the translation appears to have unfortunate repercussions in terms of how CT in mathematics is approached, especially in the first three school years, before the term programming appears in the Norwegian curriculum.

The teachers' understanding of CT and their expressed uncertainty indicate that the adoption of CT occurs in two different ways: either through sticking to the established routines and practices, where $\mathrm{CT}$ orbits the established practices (e.g. Kimmi), or through treating $\mathrm{CT}$ as a new element that causes change in the existing practices, expressed as an addon in terms of new activities (e.g., Laura, Kyra and Olivia). These two outlooks when dealing with CT in mathematics are expressed in teaching that either focuses mainly on mathematics or exclusively on programming and coding.

This is in line with Nordby et al. [28], who found that there are only a few empirical studies that document 'full integration' (i.e., mathematical concepts taught directly through CT activities, which can be used in a mutually supportive manner), perhaps due to the many demands that full integration puts on teachers. This twofold focus on either mathematics or coding/programming was also found by Israel and Lash [12], who evaluated 47 lesson plans and found that the majority did not include any integration between $\mathrm{CT}$ and mathematics. While they did identify some lessons that featured full integration, this was not the case in our study, perhaps due to the fact that CT has only recently been introduced in Norwegian classrooms. The closest thing to integration we observed was Laura's view that some CT concepts may be connected to what she already does in her mathematics classes. We next take a closer look at the CT concepts that were understood by the teachers to be potential links to the existing mathematics curriculum.

Interestingly, pattern recognition and problem solving in CT appeared to be the two concepts that were the most connected to the established mathematics information ecology in the minds of the teachers. When discussing pattern recognition, for example, Laura pointed out that this was something she already focussed on in her mathematics teaching. Rich et al. [8] reported a similar finding-teachers' perspectives of CT reflected their prior knowledge in pedagogical and instructional practices in mathematics.

In the same way, and in line with Weintrop et al. [18], who put forward seven computational problem-solving practices, the teachers in our study understood problem solving to be a connecting term between CT and mathematics. While the term problem solving has a different meaning in $\mathrm{CT}$ and in mathematics [Refvik \& Bjerke, submitted], the teachers' awareness of the similarities appeared to be a promising start, as an element that connects the ways of approaching CT to familiar and traditional approaches in mathematics. This connection is also promising in terms of Kandlhofer 
et al.'s [2] definition of AI literacy, which highlights problem solving as an essential concept in working with AI. While there are similarities between problem solving in mathematics and CT which can be used to develop a computational thinker, problem solving provides a good support in developing computational systems, which is connected to the field of machine learning. In this way, student CT skills can give implications for solving AI problems.

In line with the findings of Sands et al. [13] and Reichert et al. [29], all four teachers in our study revealed having little knowledge of CT. At the same time, they experienced having few upskilling opportunities. The Directorate of Education [31] made an online resource package available, but none of the teachers reported having used it. This suggests the need for greater awareness of resource packages available and for CT to appear more prominent in the time set aside for teachers' CT knowledge and skills.

As professionals, teachers play a pivotal role in transferring curricula goals to classroom practices. Given that our teachers addressed uncertainty both about what CT is and entails and about how it can become part of mathematics teaching, it is important that this uncertainty does not end in teachers 'blocking the gate', as was found in Larke's [33] study. This is because, as Olivia argued, CT and programming are necessary skills for meeting the digital demands of modern society; we meet such demands by learning how to control computers. This echoes several of the arguments put forward in favour of featuring CT in education, such as the idea that understanding the principles that form the basis of how computers work [8] can 'expand our understanding of ourselves as biological systems and of our relationship to the world around us' [20 p. 49]. In terms of an information ecology, CT does not yet appear to have a clear, designated role. This is needed if teachers are to be given the opportunity to be gate openers for CT.

Algorithmic thinking is mentioned only once in the Norwegian mathematics curriculum, and the term programming is used to describe the competence goals after Grade 4. In our study, the teachers referred to CT (or algorithmic thinking) as programming or coding, which is not surprising given the fact that the curriculum uses these terms. In the activities observed in the classroom, we saw the teachers make use of coding in the form of both screen-based programming activities and unplugged activities. Drawing on results from previous research, we can see these activities as promising, as past studies have reported that learning screen-based programming languages such as Scratch [36] and engaging in unplugged programming tasks [26] seem to have a positive impact on learning CT skills (but not on mathematics, as such). In addition, Kandlhofer et al. [2] found that using unplugged tasks sorting algorithms with LEGO bricks has a positive impact on introducing kindergarten and primary school students to fundamental
$\mathrm{AI} /$ computer science topics. In the same manner, various studies have demonstrated that mathematics can benefit from the implementation of CT through computer programming [28] and through building, creating and developing algorithms [17]. We found that the teachers in our study were on their way to implementing these activities in their teaching. Unfortunately, these activities are still disconnected from mathematics, and activities featuring digital tangibles were only mentioned and not used by the teachers. This lack of knowledge gives rise to concerns about the successful entry of CT into the established information ecology, as teachers may unintentionally take on the role of being gate closers.

Another concern is how the unplugged and screen-based tasks used by the teachers contribute to changing the mathematics ecology. That is, CT takes up time and space that can, at times, move the mathematical content into the background; more importantly, it can lead teachers to misinterpret or lose focus on the primary goals of the curriculum, such as when Kimmi introduced standard algorithms in Grade 4. This decision stands in stark contrast to what is recommended in the mathematics education literature [37]. This is a finding that warrants further investigations.

Keeping in mind that the inclusion of CT in the Norwegian mathematics curriculum is at an early stage and that our participants are still standing at the proverbial starting line, it appears to us that they have started walking in different directions, seemingly because they are experiencing a lack of guidance and do not feel prepared to teach the new material. Our analysis reveals two possible directions for teachers: (1) rejection and some resistance, or (2) inspiration and a willingness to engage with new ideas and activities. Despite encountering some resistance, we see promising starting points at the places where the teachers strove to embed CT into their mathematics teaching; it is hoped that focussing on and cultivating these areas will result in teachers becoming gate openers, welcoming the CT into the established mathematics ecology. What is missing is teachers' knowledge of how to merge CT and mathematics in a way that enables CT to become an integrated tool that helps students enhance their learning of mathematics. Remembering that we are still at the starting line, the goal of enabling teachers to become gate openers rather than gate closers is within reach and is crucial if CT is to become part of the established mathematics ecology.

\section{Concluding Remarks}

This study provided a lens through which to understand more about how teachers understand the integration of CT in their mathematics teaching practices. There is certainly a need to empower teachers with more knowledge, but even now, the introduction of $\mathrm{CT}$ in mathematics is promising, 
with most teachers revealing a willingness to give $\mathrm{CT}$ a place in their established mathematics ecology. However, there is a need for more research to determine how to fruitfully use CT to teach mathematics through full integration, as described by Israel and Lash [12], and how to integrate the alreadyexisting knowledge of CT-related terminology (e.g., distinguishing algorithmic thinking from standard algorithms).

As Norway has chosen mathematics as a subject in which to include $\mathrm{CT}$, this is also the arena for investigating how to better connect $\mathrm{CT}$ and $\mathrm{AI}$ concepts in educational contexts. This means that working with teachers' understanding of CT in mathematics, and the productive use of CT by students in learning mathematics, and vice versa, is crucial both to strengthen teachers' position as gate openers for CT (rather than gate closers), as well as in establishing CT as part of the mathematics ecology. This is crucial for later involvement with AI.

Funding Open access funding provided by OsloMet - Oslo Metropolitan University.

Open Access This article is licensed under a Creative Commons Attribution 4.0 International License, which permits use, sharing, adaptation, distribution and reproduction in any medium or format, as long as you give appropriate credit to the original author(s) and the source, provide a link to the Creative Commons licence, and indicate if changes were made. The images or other third party material in this article are included in the article's Creative Commons licence, unless indicated otherwise in a credit line to the material. If material is not included in the article's Creative Commons licence and your intended use is not permitted by statutory regulation or exceeds the permitted use, you will need to obtain permission directly from the copyright holder. To view a copy of this licence, visit http://creativecommons.org/licenses/by/4.0/.

\section{References}

1. Butz MV (2021) Towards strong AI. KI-Künstliche Intelligenz 35(1):91-101

2. Kandlhofer M, Steinbauer G, Hirschmugl-Gaisch S, Huber P (2016) Artificial intelligence and computer science in education: from kindergarten to university. In: 2016 IEEE frontiers in education conference (FIE), October 12-15, Eire, PA, USA. IEEE Computer Society, Washington, DC.

3. Papert S (1980) Mindstorms: children, computers, and powerful ideas. Basic Books Inc., New York

4. Gadanidis G (2017) Five affordances of computational thinking to support elementary mathematics education. JCMST 36(2):143151. https://login.ezproxy.oslomet.no/login?url=http://search. ebscohost.com/login. aspx ?direct $=$ true $\& \mathrm{db}=$ eric $\& A N=E J 115$ $4750 \&$ site $=$ ehost-live $\&$ scope $=$ site

5. Yu Y, Chen Y (2018) Design and development of high school artificial intelligence textbook based on computational thinking. OALib J 5(9):1-15

6. Wing JM (2006) Computational thinking. Commun ACM 49(3):33-35

7. Heintz F, Mannila L, Farnqvist T (2016) A review of models for introducing computational thinking, computer science and computing in K-12 education. In: 2016 IEEE frontiers in education conference (FIE), October 12-15, Eire, PA, USA. IEEE Computer Society, Washington, DC

8. Rich KM, Yadav A, Schwarz CV (2019) Computational thinking, mathematics, and science: elementary teachers' perspectives on integration. JTATE 27(2):165-205. https://login.ezproxy.oslom et.no/login?url=http://search.ebscohost.com/login.aspx?direct= true $\& \mathrm{db}=$ eric $\& \mathrm{AN}=\mathrm{EJ} 1224462 \&$ site $=$ ehost-live \&scope $=$ site

9. Bocconi S, Chioccariello A, Dettori G, Ferrari A, Engelhardt K, Kampylis P, Punie Y (2016) Developing computational thinking in compulsory education. JRC Science for Policy Report, 688.

10. Gadanidis G, Clements E (2018) Yiu C (2018) Group theory, computational thinking, and young mathematicians. Math Think Learn Int J 20(1):32-53

11. Fofang JB, Weintrop D, Walton M, Elby A, Walkoe J (2020) Mutually supportive mathematics and computational thinking in a fourth-grade classroom. In ICLS

12. Israel M, Lash $\mathrm{T}$ (2020) From classroom lessons to exploratory learning progressions: mathematics + computational thinking. Interact Learn Environ 28(3):362-382. https://login.ezproxy. oslomet.no/login?url=http://search.ebscohost.com/login.aspx? direct $=$ true $\& \mathrm{db}=$ eric $\& \mathrm{AN}=\mathrm{EJ} 1252915 \&$ site $=$ ehost-live \&scope $=$ site

13. Sands P, Yadav A, Good J (2018) Computational thinking in K-12: in-service teacher perceptions of computational thinking. In: Khine MS (ed) Computational thinking in the STEM disciplines. Springer, New York, pp 151-164

14. Brennan K, Resnick M (2012) New frameworks for studying and assessing the development of computational thinking. In: Proceedings of the 2012 annual meeting of the American Educational Research Association, April 13-17, Vancouver, Canada. AERA, Washington

15. Grover S, Pea R (2013) Computational thinking in K-12: a review of the state of the field. Educ Res 42(1):38-43

16. Haseski Hİ, Ilic U, Tugtekin U (2018) Defining a new 21st century skill—computational thinking: concepts and trends. Int Educ Stud 11(4):29-42

17. Shute VJ, Sun C, Asbell-Clarke J (2017) Demystifying computational thinking. Educ Res Rev 22:142-158. https://doi.org/10. 1016/j.edurev.2017.09

18. Weintrop D, Beheshti E, Horn M, Orton K, Jona K, Trouille L, Wilensky U (2016) Defining computational thinking for mathematics and science classrooms. J Sci Educ Technol 25(1):127-147

19. Araujo RC, Floyd L, Gadanidis G (2019) Teacher candidates' key understandings about computational thinking in mathematics and science education. JCMST 38(3):205-229. https://login.ezproxy. hioa.no/login?url=http://search.ebscohost.com/login.aspx?direct= true \&db=eric \&AN=EJ1227633\&site=ehost-live

20. Barr V, Stephenson C (2011) Bringing computational thinking to $\mathrm{K}-12$ : what is involved and what is the role of the computer science education community? ACM Inroads 2(1):48-54

21. Yadav A, Krist C, Good J, Caeli EN (2018) Computational thinking in elementary classrooms: measuring teacher understanding of computational ideas for teaching science. Comput Sci Educ 28(4):371-400. https://login.ezproxy.oslomet.no/login?url=http:// search.ebscohost.com/login.aspx?direct $=$ true \&db=eric \&AN $=$ EJ1202864\&site $=$ ehost-live\&scope $=$ site

22. Pérez-Marín D, Hijón-Neira R, Bacelo A, Pizarro C (2020) Can computational thinking be improved by using a methodology based on metaphors and scratch to teach computer programming to children? Comput Hum Behav 105:105849

23. Chalmers C (2018) Robotics and computational thinking in primary school. Int J Child Comput Interact 17:93-100

24. Martinez C, Gomez MJ, Benotti L (2015) A comparison of preschool and elementary school children learning computer science concepts through a multilanguage robot programming platform. In: Proceedings of the 2015 ACM conference on innovation and 
technology in computer science education, July 4-8, Vilnius, Lithuania. ACM, New York, NY

25. Brackmann CP, Román-González M, Robles G, Moreno-León J, Casali A, Barone D (2017) Development of computational thinking skills through unplugged activities in primary school. In: Proceedings of the 12th workshop in primary and secondary computing education, November 8-10, Nijmegen, Netherlands. ACM, New York

26. del Olmo-Muñoz J, Cózar-Gutiérrez R, González-Calero JA (2020) Computational thinking through unplugged activities in early years of primary education. Comput Educ 150:103832

27. Israel M, Pearson JN, Tapia T, Wherfel QM, Reese G (2015) Supporting all learners in school-wide computational thinking: a cross-case qualitative analysis. Comput Educ 8:263-279

28. Nordby SK, Bjerke AH, Mifsud L (2022) Computational thinking in the primary mathematics classroom: a systematic review. Digit Experiences Math Educ 1-23

29. Reichert, JT, Barone DAC, Kist M (2020) Computational thinking in K-12: an analysis with mathematics teachers. Eurasia J Math Sci Technol 16(6). https://login.ezproxy.oslomet.no/login?url= http://search.ebscohost.com/login.aspx?direct=true \&db=eric \& $\mathrm{AN}=\mathrm{EJ} 1272449 \&$ site $=$ ehost-live $\&$ scope $=$ site
30. Ludvigsen S (2015) The school of the future. Ministry of Education and Research. https://www.regjeringen.no/contentassets/ da148fec8c4a4ab88daa8b677a700292/no/pdfs/nou201520150008 000dddpdfs.pdf

31. Directorate of Education (2021) Competence package for programming and algorithmic thinking. https://www.udir.no/laringog-trivsel/lareplanverket/fagfornyelsen/kompetansepakke-forprogrammering-og-algoritmisk-tenkning/

32. Nardi BA, O’Day VL (1999) Information ecologies: using technology with heart. MIT Press, Cambridge

33. Larke LR (2019) Agentic neglect: teachers as gatekeepers of England's national computing curriculum. Br J Educ Technol 50(3):1137-1150

34. Yin RK (2014) Case study research: design and methods, 5th edn. SAGE, Los Angeles

35. Neuman WL (2006) Social research methods-qualitative and quantitative approaches, 6th edn. Pearson Education, Boston

36. Zhang L, Nouri J (2019) A systematic review of learning computational thinking through Scratch in K-9. Comput Educ 141:103607

37. Swafford J, Findell B (2001) Adding it up: Helping children learn mathematics. In: Kilpatrick J (ed) National research council, vol 2101. National Academy Press, Washington, DC 